\title{
SÍNTESE ELETROQUÍMICA DO ION FERRATO(VI)
}

\author{
Maria Augusta de Luca* \\ Instituto de Química, Universidade Federal do Rio Grande do Sul, Av. Bento Gonçalves, 9500, 91501-970 Porto Alegre - RS \\ Sérgio João de Luca e Maria Alice Santana \\ Instituto de Pesquisas Hidráulicas, Universidade Federal do Rio Grande do Sul, Av. Bento Gonçalves, 9500, 91501-970 Porto \\ Alegre - RS
}

Recebido em 22/3/02; aceito em 9/10/02

\begin{abstract}
ELETROCHEMICAL SYNTHESIS OF IRON(VI) FERRATE. The optimization of ferrate(VI) ion generation has been studied due to its favorable characteristics for application in several fields, including environmental quality control. The paper presents the best conditions for electrolytic generation of ferrate(VI) in alkaline media. An appropriate electrolyte was $\mathrm{NaOH}, 10 \mathrm{~mol} / \mathrm{L}$. Circulation of the electrolyte solution was important to avoid acidification close to the anode surface. An anode pre-cleaning with $10 \% \mathrm{HCl}$ was more efficient than a cathodic pre-polarization. Among the distinct anode materials tested, pig iron showed the best performance, allowing up to $20 \mathrm{~g} / \mathrm{L}$ of $\mathrm{Na}_{2} \mathrm{FeO}_{4}$, in $10 \mathrm{~mol} / \mathrm{L} \mathrm{NaOH}$ solution to be obtained, after $7 \mathrm{~h}$ of reactor operation, which is a concentration higher than those found in literature for alternative processes.
\end{abstract}

Keywords: ferrate(VI); electrosynthesis; anodic materials.

\section{INTRODUÇÃO}

$\mathrm{O}$ íon ferrato(VI), $\mathrm{FeO}_{4}{ }^{2-}$, por ser um forte oxidante, tem sido testado como desinfetante alternativo de águas ${ }^{1}$, efluentes e lodos, para o controle de odores em meio líquido e gasoso, para precipitação de ferro e manganês em substituição à cloração e para a desinfeção de efluentes industriais mistos ${ }^{2,3}$. O potencial padrão de redução do íon ferrato(VI) é de 2,20 V em meio básico. A sua ação desinfetante ocorre pela oxidação da molécula da água gerando radicais peróxidos, elétrons hidratados e oxidrilas, espécies altamente oxidantes. O processo de desinfecção de águas de abastecimento por este íon pode ser descrito por uma cinética de segunda ordem, sendo $\mathrm{K}_{\mathrm{CT}}=2 \times 10^{-4}$ min.NMP/100 mL para coliformes totais e $\mathrm{K}_{\mathrm{CF}}=3,7 \times 10^{-3} \mathrm{~min}$. $\mathrm{NMP} / 100 \mathrm{~mL}$ para coliformes fecais ${ }^{1}$. A grande vantagem da utilização do ferrato(VI) no tratamento de efluentes é a de não formar subprodutos clorados ${ }^{4}$ e, simultaneamente, se reduzir a ferro(III), formando $\mathrm{Fe}(\mathrm{OH})_{3}$ e seus complexos, coagulantes por excelência, removendo assim, concomitantemente, turbidez, cor e fosfatos. O poder oxidante do íon ferrato(VI) é maior que o do íon permanganato, sendo capaz de oxidar espécies reduzidas de enxofre a sulfato, amônia a nitrato, hipoclorito a cloreto bem como álcoois a aldeídos ${ }^{3}$. O íon ferrato(VI) tem sido estudado quanto à sua capacidade de descontaminar efluentes, como por exemplo, oxidar compostos reduzidos de enxofre, metais pesados e radionuclídeos. Tem igualmente sido empregado para tratar águas e efluentes contaminados por compostos orgânicos refratários e por poluentes prioritários do ar e da água².

A síntese do ferrato(VI) pode ser realizada de três maneiras básicas: a) por fusão oxidante de óxido de ferro ${ }^{5}$, b) por oxidação por via úmida do $\mathrm{Fe}(\mathrm{III})$ pelo hipoclorito, em meio fortemente alcalino ${ }^{6}$ e c) por oxidação anódica ${ }^{7}$. A oxidação por via úmida é considerada a mais prática e tem sido utilizada, entre outras coisas, para a caracterização espectral dessa espécie, para estudos da sua reatividade química $^{8}$, bem como para estudos relativos a tratamento de esgotos ${ }^{3}$.

*e-mail: augusta@vortex.ufrgs.br
Por outro lado, a oxidação anódica tem sido realizada especialmente em estudos com diferentes anodos e condições operacionais ${ }^{7,9-12}$, pois possui grande potencial de uso in loco.

A oxidação de um eletrodo de ferro é a base para a formação eletrolítica do íon ferrato(VI) de acordo com a Equação 1:

$\mathrm{Fe}+4 \mathrm{OH}^{-} \rightarrow \mathrm{FeO}_{4}^{2-}+4 \mathrm{H}^{+}+6 \mathrm{e}^{-}$

A determinação da concentração de ferrato(VI) tem sido realizada principalmente pelo método da oxidação do cromito $^{13}$. A reação do ferrato(VI) com o cromito produz cromato, o qual é convertido em dicromato, por acidificação e é, em seguida, titulado com solução padrão de sulfato ferroso, usando como indicador o dimetilamina sulfonato de sódio. Essa determinação também pode ser feita pela titulação potenciométrica de soluções de ferrato(VI) com arsenito $^{14}$, que é um método mais rápido.

Pela potencialidade de uso na área ambiental, tem-se procurado otimizar a síntese do íon ferrato(VI). Para aplicações in situ, tem-se investigado a via eletrolítica, a partir de eletrodo de ferro gusa, em reator compartimentado por uma membrana semi-permeável, em meio fortemente alcalino. Neste trabalho, discutem-se as principais variáveis de processo investigadas na otimização laboratorial da geração eletrolítica de ferrato(VI) e estabelecem-se as melhores condições para a síntese eletrolítica deste composto, de forte apelo e usos potenciais no controle da qualidade ambiental.

\section{PARTE EXPERIMENTAL}

O oxidante foi obtido em uma célula eletrolítica com duas câmaras separadas por uma membrana NAFION 475, impermeável a gases e líquidos, ionicamente condutora e quimicamente estável. As câmaras anódica e catódica, com $450 \mathrm{ml}$ de volume cada, foram carregadas com a mesma solução alcalina. Vários tempos de operação foram empregados, de 20 a 500 min, à temperatura inicial, ambiente, de $30{ }^{\circ} \mathrm{C}$. Não houve controle da temperatura ao longo dos testes. A eletrossíntese foi realizada sob condições já testadas anteriormente ${ }^{1}$, com intensidade média de corrente específica de $18 \mathrm{~mA} / \mathrm{cm}^{2}$. O mé- 
todo utilizado para análise de ferrato(VI) foi o da titulação potenciométrica com arsenito ${ }^{14}$.

Foram testados como ânodos os seguintes materiais: aço 1010, ferro fundido, ferro fundido cinzento, ferro fundido nodular e ferro gusa, os quais são todos ligas ferro-carbono que diferem entre si quanto ao teor de carbono e quanto à estrutura metalográfica. A determinação do teor de carbono em cada um desses materiais foi realizada utilizando-se, para o aço 1010, a espectrofotometria, enquanto que para as demais ligas, empregou-se um analisador de combustão com detector de infravermelho. Os eletrodos possuíam as dimensões de 80 por $100 \mathrm{~mm}$ e espessura de $6 \mathrm{~mm}$.

Como eletrólitos foram investigados o hidróxido de potássio e o hidróxido de sódio.

Investigou-se a influência dos seguintes processos de pré-tratamento do ânodo: decapagem em $\mathrm{HCl}$ a $10 \%$ por 10 min e pré-polarização catódica.

Praticamente a totalidade das eletrossínteses de ferrato(VI) relatadas na literatura empregam circulação do eletrólito, embora não estejam claras as razões deste procedimento. Em razão disto, optouse neste trabalho por realizar um experimento sem circulação do eletrólito para avaliar a influência desta operação no processo.

Com o objetivo de investigar a influência da adição do cátion potássio durante a eletrossíntese de ferrato(VI), realizou-se um experimento no qual, após $4 \mathrm{~h}$ de reação, adicionou-se uma certa quantidade de ortofosfato de potássio ao eletrólito, no sentido de precipi$\operatorname{tar} \mathrm{K}_{2} \mathrm{FeO}_{4}$ e, simultaneamente, utilizar a solução final contra a decomposição do íon ferrato(VI) na sua armazenagem ${ }^{6}$.

\section{RESULTADOS E DISCUSSÃO}

Os resultados das análise dos teores de carbono presentes nos materiais com os quais foram confeccionados os ânodos estão apresentados na Tabela 1. O cátodo foi composto de aço inox 310.

Tabela 1. Teor de carbono nos ânodos usados na eletrossíntese de ferrato(VI)

\begin{tabular}{llc}
\hline Amostra & Material & \% Carbono \\
\hline Eletrodo 1 & Aço 1010 & 0,10 \\
Eletrodo FC & Ferro Fundido Cinzento 2 & 2,85 \\
Eletrodo FN & Ferro Fundido Nodular & 3,06 \\
Eletrodo F & Ferro Fundido Cinzento 1 & 3,14 \\
Eletrodo G2 & Ferro Gusa 2 & 3,68 \\
Eletrodo G1 & Ferro Gusa 1 & 3,89 \\
\hline
\end{tabular}

A influência do teor de carbono do material do ânodo pode ser verificada através das curvas de concentração de ferrato(VI) versus tempo obtidas a partir de dados gerados durante as eletrossínteses, como pode ser observado na Figura 1. Os resultados indicam que o teor de carbono é o fator preponderante na eficiência do ânodo na eletrossíntese de ferrato(VI), mas também que a forma com que este se apresenta parece influenciar o processo. A presença de veios grandes e irregulares de grafite no ânodo de ferro gusa G1 é um indicador de que esse tipo de estrutura desfavorece a passivação do eletrodo, ou seja, favorece a dissolução do ferro através do filme passivo (dissolução transpassiva), que é o fenômeno que leva à geração do ânion ferrato(VI) em solução. Observa-se igualmente que a eficiência obtida na eletrossíntese com os distintos ânodos é tanto maior quanto maior o teor de carbono no material da liga ferro-carbono.

A comparação dos diferentes eletrólitos está representada na Figura 2. Em eletrossínteses realizadas com KOH $10 \mathrm{~mol} / \mathrm{L}$ observouse que após 1,5 h de operação a concentração do ânion ferrato(VI)

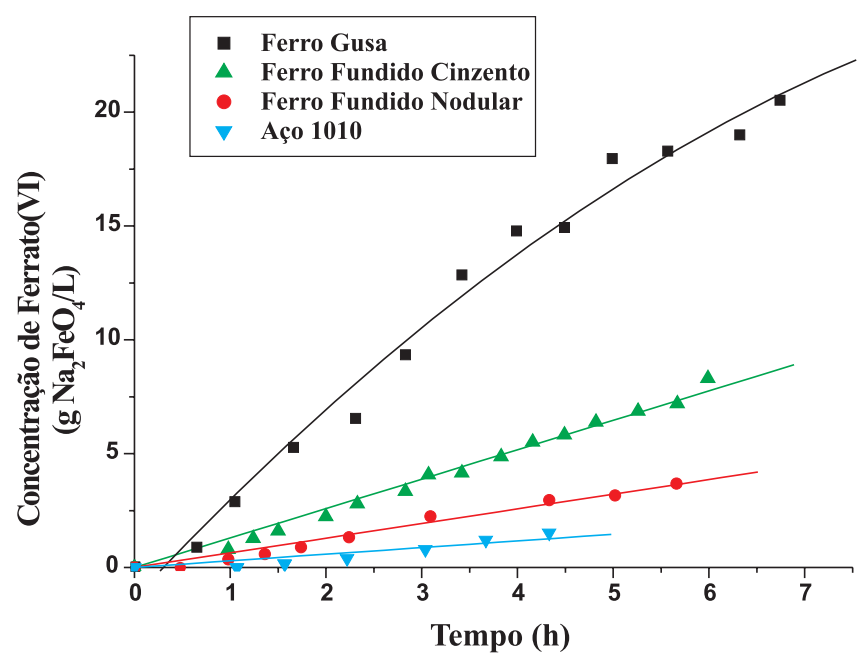

Figura 1. Concentrações de ferrato(VI) obtidas durante as eletrossínteses com distintos ânodos, em $\mathrm{NaOH} 10 \mathrm{~mol} / \mathrm{L}$, à temperatura de $30{ }^{\circ} \mathrm{C}$

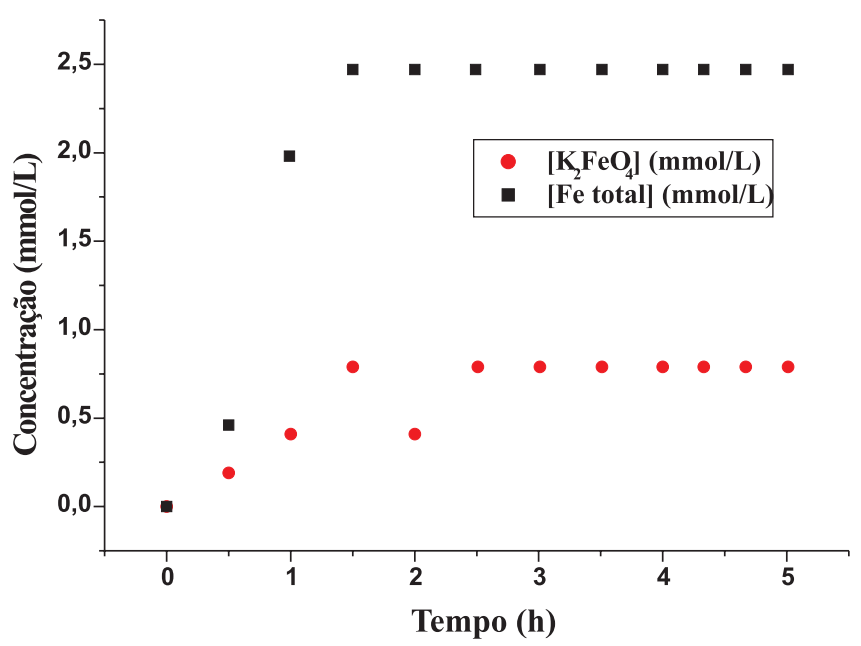

Figura 2. Variação da concentração de ferrato(VI) e de ferro total durante a eletrossíntese de ferrato(VI), realizada com ânodo de ferro gusa (G2) em $\mathrm{KOH} 10 \mathrm{~mol} / \mathrm{L}$ à temperatura de $30^{\circ} \mathrm{C}$

estabiliza-se em $0,8 \mathrm{mmol} / \mathrm{L}$ ao mesmo tempo que a concentração de ferro total estabiliza-se em 2,5 mmol/L. Esses valores são muito inferiores àqueles obtidos em condições análogas empregando-se $\mathrm{NaOH}$ $10 \mathrm{~mol} / \mathrm{L}$ como eletrólito, em que se chega a obter, após $6 \mathrm{~h}$ de eletrossíntese, $20 \mathrm{~g} / \mathrm{L}$ como $\mathrm{Na}_{2} \mathrm{FeO}_{4}$ (ou $120 \mathrm{mmol} / \mathrm{L}$ como ânion ferrato(VI)).

O efeito da concentração de hidróxido de sódio no eletrólito pode ser observado na Figura 3. O rendimento da eletrossíntese é insignificante para concentrações de $\mathrm{NaOH}$ de $1 \mathrm{~mol} / \mathrm{L}$, aumentando com a concentração deste eletrólito e atingindo o seu máximo para $8 \mathrm{~mol} / \mathrm{L}$ e $10 \mathrm{~mol} / \mathrm{L}$, diminuindo um pouco para a concentração de $14 \mathrm{~mol} / \mathrm{L}$. Com base nesses resultados, a maioria das eletrossínteses deste trabalho foram realizadas com soluções de $\mathrm{NaOH} 10 \mathrm{~mol} / \mathrm{L}$.

Os resultados dos pré-tratamentos dos ânodos podem ser observados na Figura 4. Verifica-se que na ausência de decapagem, a prépolarização prolongada por $30 \mathrm{~min}$ revelou-se prejudicial. Já a decapagem por 10 min é um pré-tratamento que aumenta o rendimento do processo, conforme se observa na Figura 5. Como a literatura $^{1}$ menciona decapagem e pré-polarização, foi empregada, entre sínteses, a decapagem seguida de 5 min de pré-polarização. 


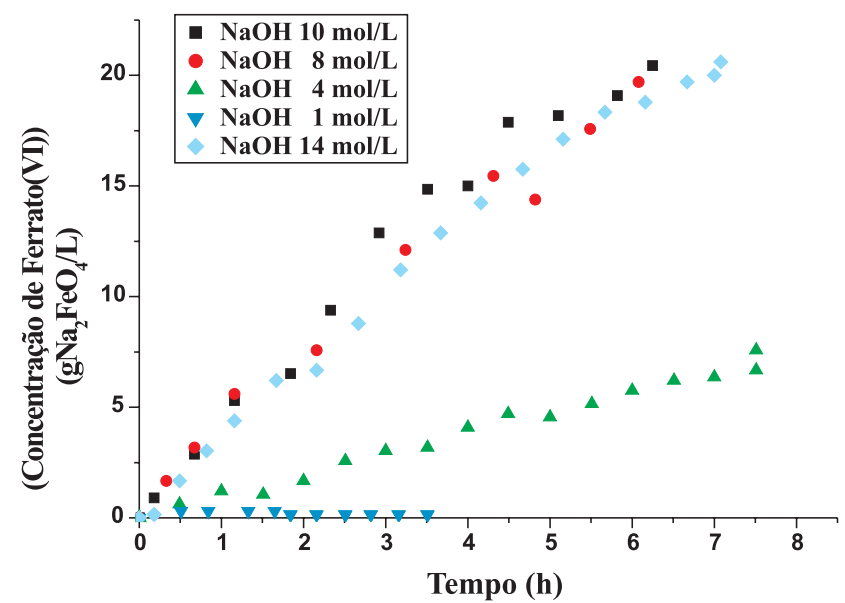

Figura 3. Variação da concentração de ferrato(VI) com ânodo de ferro gusa (G1) empregando-se como eletrólito $\mathrm{NaOH}$ com distintas concentrações

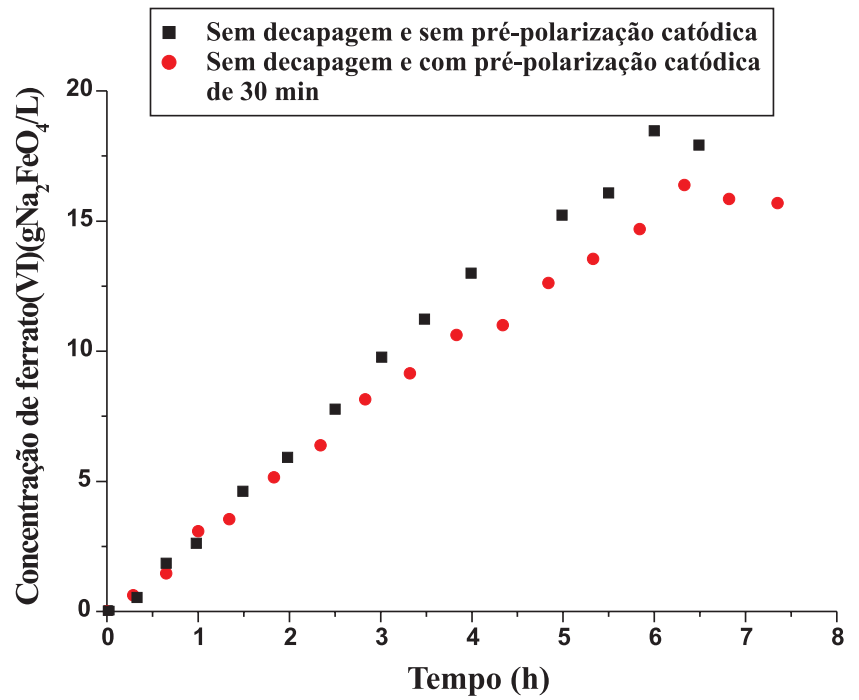

Figura 4. Influência da pré-polarização catódica do ânodo na concentração de ferrato(VI) (ânodo de ferro gusa em NaOH 10mol/L). Comparação dos tratamentos: a)sem decapagem e sem pré-polarização catódica e b)sem decapagem e com pré-polarização catódica de $30 \mathrm{~min}$

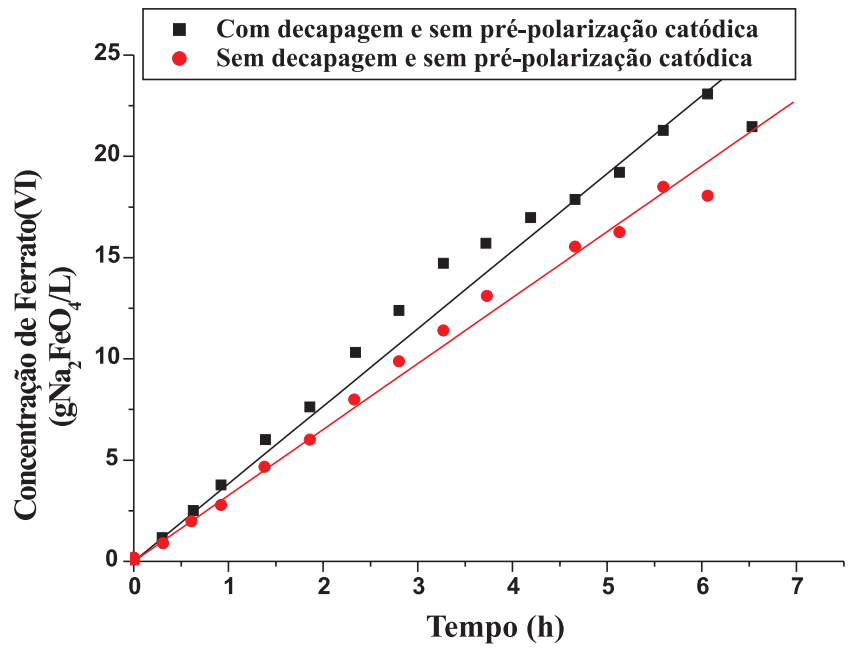

Figura 5. Influência da decapagem do ânodo na concentração de ferrato(VI) (ânodo de ferro gusa em $\mathrm{NaOH} 10 \mathrm{~mol} / \mathrm{L}$ ). Comparação dos tratamentos: a) sem decapagem e sem pré-polarização catódica e b) com decapagem e sem pré-polarização catódica
Os resultados da eletrossíntese realizada sem circulação do eletrólito são apresentados na Figura 6. Nesse experimento, o volume de anólito na célula eletroquímica foi de cerca de $200 \mathrm{~mL}$ apenas, pois o reservatório anódico externo não foi utilizado. Nos demais experimentos, em que tanto a câmara anódica quanto o reservatório externo eram utilizados, o volume total de anólito foi de cerca de $450 \mathrm{~mL}$. Naturalmente, como o processo está limitado pela área exposta do ânodo e esta é a mesma nos dois casos, a concentração de ferrato(VI) no experimento que emprega menor volume de anólito necessita ser multiplicada por um fator de correção (cerca de 0,40 ) para que os valores de concentração de ferrato(VI) e de ferro total possam ser comparados com os valores de concentração correspondentes aos demais experimentos. A Figura 6 já apresenta os valores corrigidos para a concentração de ferrato(VI) e ferro total.

A Figura 7 apresenta os resultados de uma eletrossíntese com o mesmo ânodo e a mesma concentração de eletrólito que o do experimento da Figura 6, porém desta vez com circulação do eletrólito, para efeito de comparação. Nota-se que os dois resultados são semelhantes nas primeiras $3 \mathrm{~h}$ de operação do gerador, diferindo bastante nas horas seguintes, em que a concentração de ferrato(VI) e de ferro

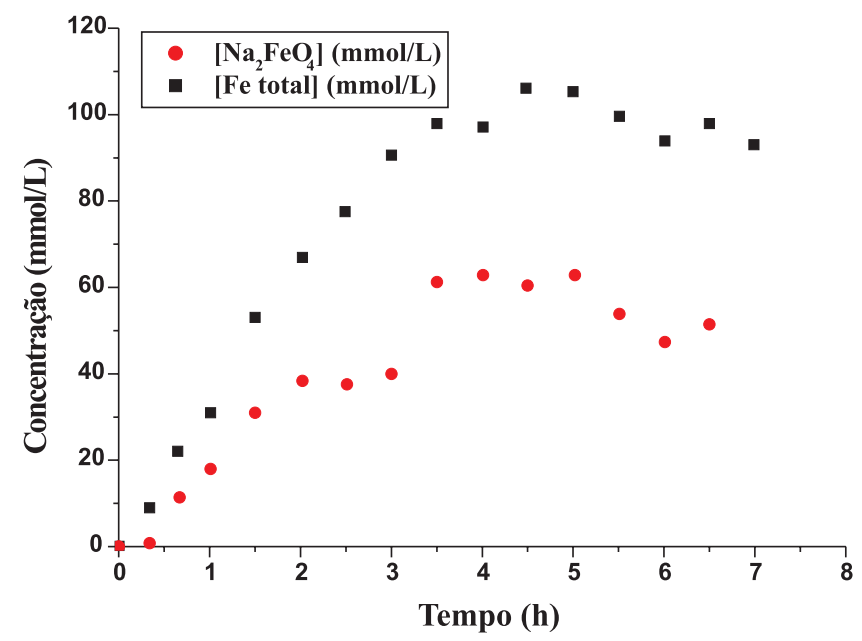

Figura 6. Concentração de ferrato(VI) em experimentos sem circulação do eletrólito, com ânodo de ferro gusa em $\mathrm{NaOH} 10 \mathrm{~mol} / \mathrm{L}$ (com decapagem e pré-polarização catódica de $5 \mathrm{~min}$ )

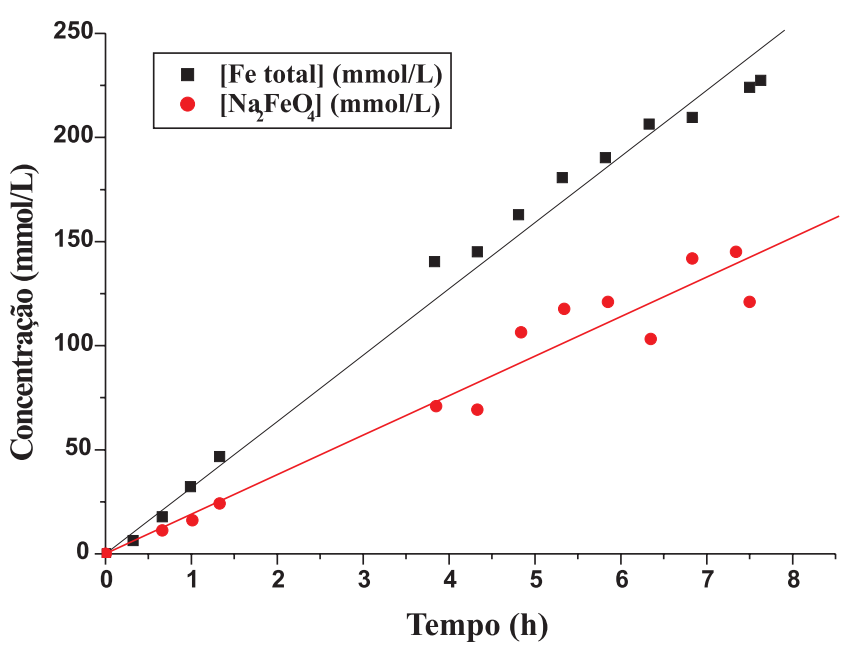

Figura 7. Concentração de ferrato(VI) com ânodo de ferro gusa em $\mathrm{NaOH}$ $10 \mathrm{~mol} / \mathrm{L}$, (com decapagem, pré-polarização catódica de $5 \mathrm{~min}$ ), com circulação do eletrólito (célula eletroquímica com os reservatórios anódico e catódico) 
total atinge um patamar seguido de uma queda para o caso em que não há circulação do eletrólito, enquanto que ambas continuam a subir com o tempo de operação para o caso que se emprega eletrólito circulante. O patamar e a queda na concentração de ferrato(VI) e ferro total no experimento sem circulação do eletrólito foram acompanhados por aumento da temperatura do eletrólito, o qual atingiu $40{ }^{\circ} \mathrm{C}$ após $5 \mathrm{~h}$, chegando a $45^{\circ} \mathrm{C}$ após $7 \mathrm{~h}$, na temperatura ambiente de $30{ }^{\circ} \mathrm{C}$. Sabe-se que com o aumento da temperatura a valores superiores a $40{ }^{\circ} \mathrm{C}$ o ferrato(VI) começa a sofrer decomposição a hidróxido de ferro $^{6}$, porém não foi constatada a ocorrência de precipitação no fundo da câmara anódica, o que indica que não foi esse o principal motivo da queda de eficiência do processo a partir de $3 \mathrm{~h}$ de operação. Provavelmente, a não circulação do eletrólito leve a uma acidificação local da solução próxima ao ânodo (devido à reação concorrente de evolução de oxigênio, que ocorre em paralelo com a reação de dissolução transpassiva do ferro a ferrato(VI)), prejudicial à geração de ferrato(VI). No experimento sem circulação do eletrólito, a máxima concentração de ferrato(VI) foi igual a $64 \mathrm{mmol} / \mathrm{L}$ (ou 10,5 g/L de $\mathrm{Na}_{2} \mathrm{FeO}_{4}$ ), tendo sido obtida após 4 h de operação, enquanto que no experimento em que se empregou eletrólito circulante, após $7 \mathrm{~h}$, tinha-se $140 \mathrm{mmol} / \mathrm{L}$ de ferrato(VI) (ou $23 \mathrm{~g} / \mathrm{L}$ de $\mathrm{Na}_{2} \mathrm{FeO}_{4}$ ) e a tendência da curva ainda era crescente, indicando que se o experimento prosseguisse por mais tempo, essa concentração poderia aumentar ainda mais. Esses resultados mostram, portanto, a conveniência de se utilizar eletrólito circulante durante a eletrossíntese de ferrato(VI).

Com relação à influência da adição do cátion potássio durante a eletrossíntese do íon ferrato(VI), esperava-se que pudesse ocorrer a formação de ferrato(VI) de potássio a partir de ferrato(VI) de sódio, com conseqüente precipitação de ferrato de potássio (pois este é menos solúvel que o ferrato de sódio), o que não foi observado. Efetivamente não houve nenhuma modificação no processo de eletrossíntese como consequiência da adição do sal de potássio, conforme se observa na Figura 8.

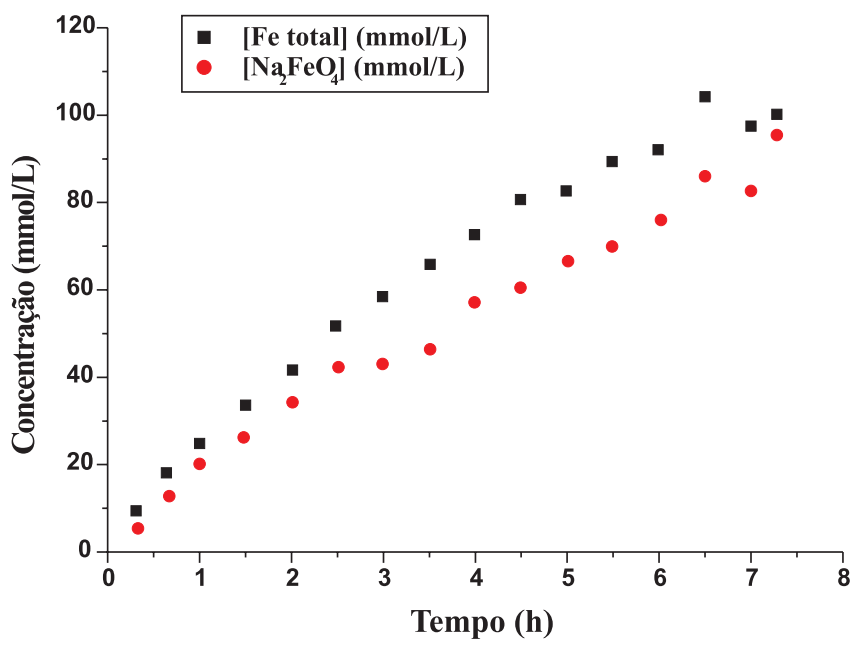

Figura 8. Concentração de ferrato(VI) com ânodo de ferro gusa em $\mathrm{NaOH}$ $10 \mathrm{~mol} / \mathrm{L}$, (com decapagem, pré-polarização catódica de $5 \mathrm{~min}$ ). Após $4 \mathrm{~h}$ de operação da célula adicionou-se 4,35g de $\mathrm{K}_{2} \mathrm{HPO}_{4}$ ao reservatório anódico

\section{CONCLUSÕES}

Os testes realizados com uma célula eletroquímica, visando otimizar o processo de geração eletrolítica de ferrato(VI), levam às seguintes conclusões:
A natureza do material do ânodo é crucial para a eficácia da geração eletrolítica. Dentre as ligas ferro-carbono investigadas (aço 1010 , ferro fundido cinzento, ferro fundido nodular e ferro gusa) a que apresentou melhor desempenho foi a de ferro gusa, cujo teor de carbono era o mais elevado (3,7 a 3,9\% de C) e cuja análise metalográfica revelou a presença de veios de grafite. Esse resultado mostra o quanto o teor de grafite e a forma como este se apresenta na liga ferro-carbono determinam a velocidade do processo de transformação do ferro, o qual ocorre em meio fortemente alcalino pela aplicação de potenciais elevados de oxidação, gerando o íon $\mathrm{Fe}(\mathrm{VI})$ que passa do ânodo para a solução na forma do ânion ferrato $\left(\mathrm{FeO}_{4}^{2-}\right)$.

Quanto à natureza do eletrólito, investigou-se $\mathrm{KOH}$ e $\mathrm{NaOH}$, tendo-se concluído que com $\mathrm{KOH}$ a eficiência do processo de geração eletrolítica de ferrato é muito inferior àquela obtida com $\mathrm{NaOH}$. Por exemplo, empregando-se $\mathrm{KOH} 10 \mathrm{~mol} / \mathrm{L}$ como eletrólito e o ânodo de ferro gusa, não se chega a obter $1 \mathrm{mM}$ de ferrato após $5 \mathrm{~h}$ de operação, enquanto que com $\mathrm{NaOH} 10 \mathrm{~mol} / \mathrm{L}$, obtém-se aproximadamente $100 \mathrm{mmol} / \mathrm{L}$ de ferrato após o mesmo tempo de operação. A razão da forte influência do cátion $\left(\mathrm{K}^{+}\right.$ou $\left.\mathrm{Na}^{+}\right)$presente no eletrólito deve estar ligada à natureza do filme de passivação formado sobre o ânodo que, no caso do $\mathrm{Na}^{+}$, deve ser mais vulnerável facilitando a transpassivação, isto é, levando à dissolução do ferro através desse filme, fenômeno responsável pela presença do ânion ferrato(VI) em solução.

Não se observou o aparecimento de nenhum precipitado de ferrato(VI) de potássio durante os testes realizados com $\mathrm{KOH}$ como eletrólito, eliminando-se assim a possibilidade de ter ocorrido a formação de muito ferrato(VI) de potássio como precipitação posterior (devido à sua menor solubilidade). Conclui-se que efetivamente pouco ferrato(VI) se forma quando o eletrólito é $\mathrm{KOH}$.

Por outro lado, tendo-se o $\mathrm{NaOH}$ como eletrólito de excelência, obtém-se boa eficiência para o processo de geração eletrolítica de ferrato. Foram investigadas diferentes concentrações de $\mathrm{NaOH}$, na faixa de 1 a $14 \mathrm{~mol} / \mathrm{L}$, e constatou-se que o rendimento do processo aumenta com o aumento da concentração de $\mathrm{NaOH}$ de $8 \mathrm{~mol} / \mathrm{L}$ até $10 \mathrm{~mol} / \mathrm{L}$, voltando a diminuir para a concentração de $14 \mathrm{~mol} / \mathrm{L}$.

Investigou-se também o papel da circulação do eletrólito no processo, tendo-se concluído que a ausência de circulação leva a um rendimento do processo inferior àquele que se obtém com o eletrólito circulante. Essa diferença, que é mais acentuada a partir de $4 \mathrm{~h}$ de eletrossíntese, pode estar associada a um dos dois fatores seguintes (ou a ambos):

(a) a acidificação da solução próxima à superfície do ânodo (decorrente da reação paralela de evolução de $\mathrm{O}_{2}$ ), a qual se acentua quando não há a renovação do eletrólito próximo ao ânodo, ou seja, quando não há circulação do eletrólito;

(b) a um aquecimento da solução, que se faz notar a partir de $3 \mathrm{~h}$ de operação e que poderia provocar o decaimento da concentração de ferrato em solução a partir de então.

De qualquer forma, os resultados indicam claramente que a circulação do eletrólito é um fator importante para a obtenção de boa eficiência no processo de eletrossíntese de ferrato.

A eficiência do processo de eletrossíntese de ferrato(VI) de potássio é aumentada se o ânodo for submetido a um pré-tratamento, entre sínteses, que consiste em submetê-lo à decapagem durante 10 min em $\mathrm{HCl} 10 \%$ (e posteriormente lavá-lo abundantemente com água), antes de ter iniciado o processo de eletrossíntese. Investigouse também a possibilidade de empregar outro tipo de pré-tratamento, a pré-polarização catódica; no entanto, os resultados mostraram que a pré-polarização catódica por até $20 \mathrm{~min}$ tem pouca influência na eficiência do processo.

O conjunto dos resultados obtidos revela que a geração eletrolítica de ferrato(VI) pode ser realizada como boa eficiência, em solução 
fortemente alcalinas de $\mathrm{NaOH}$, chegando-se a obter $20 \mathrm{~g} / \mathrm{L}$ de $\mathrm{NaFeO}_{4}$ em $\mathrm{NaOH} 10 \mathrm{~mol} / \mathrm{L}$, após 7 h de operação da célula com ânodo de ferro gusa.

\section{REFERÊNCIAS}

1. De Luca, M. A.; Relatório Final de Pesquisa MCT/FINEP/CNPQ/CEF/ PROSAB II, Tema 1, Rio de Janeiro, 2000.

2. De Luca, S. J.; Chao, A. C.; Smallwood, C.; J. Environ. Eng. Div. ASCE 1983, 109, 36.

3. De Luca, S. J.; Cantelli, M.; De Luca, M. A.; Water Sci. Technol. 1992, 26, 2077.

4. White, D. A; Franklin, G. S.; Environ. Technol. 1998, 19, 1157.

5. Deduschenko, S. K.; Kholodovskaya, L. N.; Perfiliev, Y. D.; Kiselev, A. A.; Saphyrin, Y. M.; Kamozin, P. N.; Lemesheva, D. G.; J. Alloys Compd. 1997, 262, 78 .
6. Thompsom, G. V; Ockermann, L. T.; Schreyer, J. M.; J. Am. Chem. Soc. 1951, 73, 1379.

7. Denvir, A.; Pletcher, D.; J. Appl. Electrochem. 1996, 26, 815.

8. Tsapin, A. I.; Goldfeld, M. G.; McDonald, G. D.; Nealson, K. H.; Moskovitz, B.; Solheid, P.; Kemner, K. M.; Kelly, S. D.; Orlandini, K. A.; Icarus 2000, 147, 68.

9. Bouzek, K.; Schmidt, M. J.; Wraag, A. A.; J. Chem. Biotechnol. 1999, 74, 1188.

10. Denvir, A.; Pletcher, D.; J. Appl. Electrochem. 1996, 26, 823.

11. Bouzek, K.; Lipovska, M.; Schmidt, M. J.; Rousar, I.; Wraag, A. A.; Electrochim. Acta 1998, 44, 547.

12. Bouzek K.; Flower L.; Rousar I.; Wraag, A. A.; J. Appl. Electrochem. 1999, 29, 569 .

13. Schreyer, J. M.; Thompson, G. W.; Ockerman, L. T.; Anal. Chem. 1950, 22,691 